\title{
Correction to: Signification of Systemic Immune-Inflammation Index for prediction of prognosis after resecting in patients with colorectal cancer
}

Saori Yatabe ${ }^{1} \cdot$ Ken Eto $^{1}$ (D) Koichiro Haruki $^{1} \cdot$ Hiroaki Shiba $^{1} \cdot$ Makoto Kosuge $^{1} \cdot$ Masahisa Ohkuma $^{1} \cdot$ Daisuke Ito $^{1}$. Yasuhiro Takeda ${ }^{1} \cdot$ Hiroshi Sugano $^{1} \cdot$ Shigemasa Sasaki $^{1} \cdot$ Katsuhiko Yanaga $^{1}$

Published online: 2 June 2020

(C) Springer-Verlag GmbH Germany, part of Springer Nature 2020

\section{Correction to: International Journal of Colorectal Disease} https://doi.org/10.1007/s00384-020-03615-w

The authors regrets that there is a typo error on Tables 1,2 and 3 of their published paper. The Table entry "SIII" should have been "SII" as indicated in the footnote section of the Tables as "SII = systematic immune-inflammation index". The authors have requested that this be noted.

The remainder of the article remains unchanged.

The online version of the original article can be found at https://doi.org/ 10.1007/s00384-020-03615-w

Ken Eto

etoken@jikei.ac.jp

1 Departments of Surgery, Jikei University School of Medicine,

3-25-8, Nishi-shinbashi, Minato-ku, Tokyo 105-8461, Japan 